\title{
ANTONIO DE VILLEGAS Y JERÓNIMO DE MILLIS: ACUERDOS Y DESACUERDOS EN TORNO A LA SEGUNDA EDICIÓN DEL INVENTARIO
}

EDUARDO TORRES COROMINAS

Universidad Autónoma de Madrid

El avance de los estudios filológicos ha permitido descubrir, en las últimas décadas, las posibilidades de investigación que ofrecen diversas disciplinas auxiliares como la bibliografía material, la sociología de la edición o la historia del derecho español de prensa e imprenta a la hora de conocer las variadísimas circunstancias que influyeron en la génesis, composición y posterior distribución de los libros impresos en el Siglo de Oro. La utilidad de estas nuevas vías de aproximación al objeto de estudio resulta evidente desde el momento en que se constata el peso que ejercieron los factores técnicos, comerciales o legislativos en la configuración definitiva de numerosos textos literarios.

En efecto, para explicar debidamente la forma y contenido del libro al que dedicamos el presente trabajo - la segunda edición del Inventario de Antonio de Villegas, impresa en Medina del Campo en 1577- se hace necesario recurrir a muy diversos enfoques que, en un momento previo, desbrozan el camino a la lectura crítica y evitan errores manifiestos de interpretación. Las expectativas creadas por estos estudios para progresar con paso firme en el conocimiento son inmensas, pero se hallan sujetas, inevitablemente, al azar de las ediciones y documentos conservados en archivos y bibliotecas. No obstante, el reciente hallazgo de diversos protocolos notariales - desconocidos hasta la fecha- en el Archivo Histórico Provincial de Valladolid ha permitido desvelar las circunstancias y dimensiones exactas del proyecto editorial que dio lugar al libro impreso que nos ocupa.

Es nuestra intención, por tanto, relatar con estos apoyos las fortunas y adversidades del segundo Inventario de Villegas, curiosísima pieza literaria donde se inserta, entre otros materiales, la versión del Abencerraje más prestigiada por la crítica moderna. Esta edición medinense, financiada por el poderoso mercader de libros Jerónimo de Millis, no es, sin embargo, más que el último 
eslabón de una tradición editorial que es preciso reconstruir primero si se quieren juzgar con perspectiva los procedimientos llevados a cabo en la postrera forma de la obra.

Y para dar con los orígenes de esta historia, hay que remontarse a la lejana primavera de 1551, casi tres décadas atrás, cuando Antonio de Villegas, vecino de Medina del Campo, se dirige a la Cámara de Castilla con el fin de obtener, por vez primera, privilegio de impresión para sus obras. Según sus propias palabras — recogidas en un memorial del Archivo General de Simancas ${ }^{1}$ — se trata de un libro de ciertas obras poéticas donde alternan versos al estilo tradicional castellano con otros compuestos al nuevo modo italiano. Un variado cancionero, pues, es lo que pretende imprimir Villegas en 1551, a imagen y semejanza de lo que se había hecho pocos años antes con las obras de Boscán y Garcilaso en la misma Medina ${ }^{2}$.

Los trámites, sin embargo, se alargan en el seno de la administración, y tanto el censor al servicio de la Cámara, fray Felipe de Urriés, como los miembros del Consejo de Inquisición - a quienes, de forma excepcional, se consulta sobre el particular ${ }^{3}$ - coinciden en censurar parte de los contenidos, que califican como ofensivos o inapropiados al tratar en cosas de Dios. Finalmente, y tras eliminar los pasajes señalados en el escrutinio, Antonio de Villegas recibe autorización oficial para llevar sus versos a la imprenta. No obstante, en los diez años de vigencia del privilegio no hará uso del mismo. Bien por decisión personal, bien por incapacidad para encontrar editor, lo cierto es que en dicho período su obra no pasa a letras de molde y el plazo de la licencia expira sin que el proyecto culmine con una edición impresa.

A la altura de 1565 los intentos de Villegas tendrán desenlace más afortunado. Impulsado por poderosas motivaciones personales - la muerte de la amada $^{4}$ - y animado por una coyuntura política más favorable — los ebolistas

${ }^{1}$ El memorial de la Cámara de Castilla donde se recogen las gestiones realizadas por Antonio de Villegas en 1551 fue presentado en Eduardo Torres Corominas, «1551: el primer «inventario» de Villegas», Edad de Oro, XXIV, 2005, págs. 407-433.

${ }^{2}$ El género editorial de los cancioneros personales o individuales, que se configura en las letras españolas a mediados del siglo XVI, está inspirado en el modelo que establecieron los impresos de Boscán y Garcilaso a partir de 1543, tal y como ha estudiado Juan Montero Delgado, «Sobre imprenta y poesía a mediados del XVI (con nuevos datos sobre la princeps de las obras de Jorge de Montemayor)», Bulletin Hispanique, CVI, 1, 2004, págs. 81-102.

${ }^{3} \mathrm{La}$ consulta resulta excepcional desde que se establece, por estas mismas fechas, la división de funciones entre el Consejo de Castilla - censura previa y concesión de licencias de impresión- y el Consejo de Inquisición — examen de las obras en circulación - en el aparato de control de la Monarquía, tal y como explica José Martínez Millán, «Aportaciones a la formación del Estado Moderno y a la política española a través de la censura inquisitorial durante el período 1480-1559», La Inquisición española. Nueva visión, nuevos horizontes, Joaquín Pérez Villanueva, dir., Madrid, Siglo XXI, 1980, págs. 537-578.

${ }^{4}$ La reciente muerte de la amada se deduce de las propias palabras de Villegas, quien dirigiéndose a su hijo —el mismo Inventario - en el Prólogo, vv. 21-25, confiesa que: «Ella fue 
han sustituido a las facciones más intransigentes al frente de la Monarquía hispana ${ }^{5}$ - logra llegar a un acuerdo con Mateo del Canto, librero de Medina del Campo, para sacar adelante la edición. Ponen sobre la mesa todas las composiciones salidas de la pluma de Villegas desde hace más de veinte años y, añadiendo aquí y suprimiendo allá, consiguen dar sentido a una pieza de nuevo cuño elaborada a partir de materiales que, en origen, fueron concebidos de forma independiente ${ }^{6}$. Esta antología de versos, este «inventario», ofrece además dos textos en prosa que completan el volumen: Ausencia y soledad de amor ${ }^{7}$, que comparte temas y tono con los poemas amorosos; y una tercera versión del Abencerraje que, situada a modo de apéndice tras el cancionero, fue añadida a última hora para incrementar las posibilidades comerciales de la obra ${ }^{8}$.

viva centella/ del fuego en que me quemé;/ no alcanzaste a conocella,/ que más te preciaras d'ella,/ que de mí que te engendré».

${ }^{5}$ La pertenencia de Antonio de Villegas al círculo cortesano de los ebolistas se prueba por muy distintas vías. En primer lugar, por el hecho de que al pie del privilegio otorgado en 1565 se descubra que aquella merced real fue concedida «A suplicación de Antonio Gómez de Erasso», quien a la sazón era hijo del secretario Francisco de Eraso. Desde el regreso de Felipe II a la Península (1559), tanto Francisco de Eraso como Ruy Gómez de Silva constituían la cabeza de la facción ebolista, cuyo período de hegemonía en la Corte española se prolonga hasta estas mismas fechas (1565) para decaer después con el ascenso de Diego de Espinosa. Del mismo modo, las inclinaciones políticas del escritor quedan de manifiesto con la dedicatoria de varios poemas laudatorios a prominentes ebolistas como la princesa doña Juana o el duque de Sessa. Finalmente, la sintonía existente entre la ideología del grupo — humanista, tolerante e integradora- y el sentido profundo del Abencerraje hacen pensar en una afinidad que superaba los lazos del mero clientelismo. Para seguir la trayectoria del partido de Éboli, puede consultarse el trabajo de José Martínez Millán, «Grupos de poder en la corte durante el reinado de Felipe II: la facción ebolista, 1554-1573», Instituciones y elites de poder en la monarquía hispana durante el siglo XVI, José Martínez Millán, ed., Madrid, Universidad Autónoma, 1992, págs. 137-197, mientras que la figura de Francisco de Eraso ha recibido tratamiento particular en Carlos Javier de Carlos Morales, «El poder de los secretarios reales: Francisco de Eraso», La corte de Felipe II, José Martínez Millán, ed., Madrid, Alianza, 1994, págs. 107-148.

${ }^{6}$ Los modos de transmisión de la poesía del Siglo de Oro y la forma de componer estos volúmenes a partir de piezas sueltas fueron explicados, de forma reveladora, por Antonio Rodríguez Moñino, Construcción crítica y realidad histórica en la poesía española de los siglos XVI y XVII, Madrid, Castalia, 1968. Después, otros autores han incidido en la materia, como Pablo Jauralde Pou, «El público y la realidad histórica de la literatura española de los siglos XVI y XVII», Edad de Oro, I, 1982, págs. 55-64; Jaime Moll, «Transmisión y público de la obra poética», Edad de Oro, IV, 1985, págs. 71-85; Víctor Infantes, «En busca del lector perdido: la recepción de la poesía culta (1543-1600)», Edad de Oro, XII, 1993, págs. 43-54; Isaías L. Rivers, «La poesía culta y sus lectores», Edad de Oro, XII, 1993, págs. 267-279; y Juan Montero Delgado, «Sobre imprenta y poesía a mediados del XVI...», op. cit.

${ }^{7}$ Esta pieza de tradición pastoril fue editada y comentada por Francisco López Estrada, «Estudio y texto de la narración pastoril: Ausencia y soledad de amor, del Inventario de Villegas», Boletín de la Real Academia Española, XXIX, 1949, págs. 99-133.

${ }^{8}$ La más que probable redacción tardía del Abencerraje de Villegas — la versión Crónica circula desde 1561, la versión Diana desde 1562 - junto al difícil acomodo de la pieza en la estructura de la obra - no participa en la distribución general de materiales, sino que se yuxtapone a ella como elemento heterogéneo-y la frecuencia de estas estrategias editoriales - Francis- 
Sólo tras configurar la estructura definitiva del Inventario de acuerdo con el librero, el autor presenta a las autoridades este variado corpus literario. Frente a las dificultades pasadas catorce años atrás, los trámites burocráticos se resuelven con sorprendente celeridad en 1565 . En pocos días, la Cámara de Castilla concede la merced solicitada sin cuestionar una palabra del Inventario.

Antes de finalizar el año, el cancionero sale de la imprenta de Francisco del Canto en su forma original. Se trata de un libro en cuartos preparado con esmero que ya disfruta de las nuevas letrerías romanas recientemente adquiridas por el impresor ${ }^{9}$. En la portada, un llamativo escudo real y la dedicatoria a Felipe II adornan y dan prestancia a un producto editorial para el que no se han escatimado recursos. En efecto, la holgura del formato, el tamaño de los tipos, la calidad de los grabados y el cuidado de la composición dan como resultado un volumen más que notable en lo que se refiere a su materialidad ${ }^{10}$.

Tras nueve años de celebrada existencia ${ }^{11}$, sin embargo, el tiempo de la licencia está a punto de agotarse. Corre el año 1574 y Antonio de Villegas no desea perder el control sobre su obra. Por ello, ha de dirigirse una vez más a la Cámara de Castilla para solicitar la renovación del privilegio. En ese punto comienza la historia del segundo Inventario, que sólo en 1577 —y tras superar numerosas dificultades - verá la luz en la misma imprenta medinense de Francisco del Canto ${ }^{12}$.

co Fernández de Córdoba, sin ir más lejos, recurre al mismo Abencerraje tres años antes para incrementar los alicientes de la Diana impresa en Valladolid - parecen indicar que los intereses comerciales del editor estimularon la inserción de la novelita morisca al final del Inventario. Desde un punto de vista formal, la composición del Abencerraje de Villegas a partir de las dos versiones anteriores fue hipótesis defendida por Keith Whinnom, «The Relationship of the three texts of El Abencerraje», The Modern Languaje Rewiew, LIV, 1959, págs. 507-517.

${ }^{9}$ Como observa Cristóbal Pérez Pastor, La imprenta en Medina del Campo, Madrid, Sucesores de Rivadeneyra, 1895, pág. 486, ed. facsímil de Pedro M. Cátedra, Salamanca, Junta de Castilla y León, 1992, la secuencia de obras impresas por Francisco del Canto demuestra que, en sus inicios, sólo disponía de letrerías góticas, con las cuales preparó, por ejemplo, su temprana edición de Lazarillo de Tormes (1554). Más adelante, adquirió las bellas letrerías romanas con que compuso el Inventario (1565), y durante algún tiempo ambos estilos convivieron en su taller —un año más tarde, en 1566, aún imprime la Crónica de Fernando III en letra gótica-. Andados los años, sin embargo, los nuevos juegos desterraron por completo a los antiguos, cuyo marcado arcaísmo hizo que fueran cayendo paulatinamente en desuso.

${ }^{10} \mathrm{La}$ edición príncipe, Antonio de Villegas, Inventario, Medina del Campo, Francisco del Canto, 1565, se conserva a través de un único ejemplar que guarda la Biblioteca Nacional de Madrid bajo la signatura R 2159. La única edición moderna de la misma fue ofrecida hace más de medio siglo en el seno de una colección para bibliófilos: Antonio de Villegas, Inventario, Francisco López Estrada, ed., Madrid, Joyas bibliográficas, 1955-1956.

11 Noticias muy relevantes en torno a la recepción del Inventario en Valladolid han sido conocidas recientemente gracias al trabajo de Juan Montero Delgado, «Noticia de un texto recuperado: la invectiva de Damasio de Frías contra Antonio de Villegas y su «Inventario»», Voz y Letra, XIV, 2, 2003, págs. 79-98, donde se recogen datos cruciales para la biografía del autor.

${ }^{12}$ De la segunda edición, Antonio de Villegas, Inventario, Medina del Campo, Francisco del Canto, 1577, sólo ha sobrevivido el ejemplar de la Biblioteca Nacional de Madrid, R 7834. 
Como en tantas ocasiones, sabemos de los movimientos iniciales gracias a las noticias contenidas en los preliminares de la obra. En ellos se transcribe el nuevo privilegio, otorgado por Felipe II a 20 de julio de 1574, por el cual se renuevan los derechos del autor para la Corona de Castilla por tiempo de ocho años. Los futuros impresos habrán de coincidir con el ejemplar rubricado por Pedro del Mármol, escribano de Cámara, sobre el cual se realizó el examen de la censura.

A la hora de solicitar la renovación del privilegio, pues, Antonio de Villegas tuvo que presentar de nuevo un original cuyo texto serviría de modelo para las sucesivas ediciones de la obra. Dadas las concomitancias entre los Inventarios de 1565 y 1577 - y considerando el modo de trabajo de aquellos artesanos de la imprenta ${ }^{13}$ - es muy probable que el ejemplar entregado a la Cámara de Castilla en 1574 perteneciera a la edición príncipe. Y es que los manuscritos poéticos, una vez trasladados a letras de molde, pasaban a un segundo plano y no solían ser utilizados en sucesivas ediciones, ya que éstas casi siempre se realizaban sobre la base de impresos anteriores, como parece ser el caso $^{14}$. Así, Pedro del Mármol, escribano de Cámara de Su Majestad, rubricó, con casi toda seguridad, un ejemplar del primer Inventario para que Antonio de Villegas $\longrightarrow$ o quien su poder hubiere - pudiera promover nuevas ediciones en Castilla.

Dicha empresa, sin embargo, no cobró forma hasta tres años más tarde, cuando nuevas composiciones se adhirieron al texto original. En el verano de 1574, probablemente, el escritor medinense no pensara en tan lejanos plazos. ¿Qué sucedió para retrasar tanto el proyecto? Las investigaciones en el Archivo Histórico Provincial de Valladolid, una vez más, parecen dar con la respuesta.

Si pensamos en la génesis de este nuevo producto editorial, inevitablemente habremos de volver la mirada hacia el mundo editorial de Medina del Campo y, en particular, hacia los personajes que hicieron posible el surgimiento de la princeps, pues ellos — los hermanos del Canto- serían, en principio, los más indicados para prolongar la triunfante andadura del Inventario. Decimos triunfante, sí, porque de haber sido de otra manera, jamás el escritor habría solicitado la renovación del privilegio.

El contexto en que se mueve Villegas, no obstante, no puede ser más favo-

13 Sobre el particular, véase el trabajo de Sonia Garza Merino, «La cuenta del original», Imprenta y crítica textual en el siglo de oro, Francisco Rico, ed., Valladolid, Centro para la Edición de Clásicos Españoles, Universidad de Valladolid, 2001, págs. 65-95.

${ }^{14} \mathrm{El}$ empleo de originales impresos como base para las sucesivas ediciones de una obra es una de las principales conclusiones del estudio empírico realizado por Pablo Andrés Escapa, Elena Delgado Pascual, Arantxa Malvadi y José Luis Rodríguez Montederramo, «El original de imprenta», Imprenta y crítica textual en el siglo de oro, op. cit., págs. 29-64. 
rable. A mediados de la década de 1570 , el negocio editorial medinense ${ }^{15}$ se encuentra en pleno apogeo y son muchos los libreros que dirigen sus actividades mercantiles y editoriales desde la villa de las ferias. Superado el momento de recesión ${ }^{16}$ que sucedió a la pragmática de $1558^{17}$ y al Índice inquisitorial de Fernando de Valdés ${ }^{18}$ (1559), el ritmo de impresiones se recupera según avanza la década de $1560 \mathrm{y}$, ya en 1572, la actividad parece haberse reestablecido por completo: quince librerías permanecen abiertas en tal fecha cuando Antonio Vela, corregidor de la villa, inicia por sorpresa una visita. Echa el cierre a todas las tiendas de libros y procede a revisar los breviarios y misales que se venden en ellas. El nombre de los grandes libreros — Jerónimo de Millis, Pierre Landry, Diego de Espinosa o Benito Boyer- aparece ya en las actas de aquella inspección ${ }^{19}$. No hay duda, Medina del Campo se halla en el período de máximo esplendor para los mercaderes de libros de alcance internacional, los cuales acumulan decenas de miles de ejemplares en sus trastiendas para distribuirlos por toda Castilla. En este período, el tráfico crece, se intensifica y, ahora más que nunca, debe organizarse a través de una tupida red de sucursales establecidas en ciudades como Salamanca, Valladolid, Alcalá, Toledo o Sevilla. Medina del Campo se ha constituido en el centro rector del comercio de libros para el noroeste peninsular. Ningún lugar más adecuado, por consiguiente, a la altura de 1574, para encontrar editor que apostara por el Inventario.

15 Sobre el negocio editorial medinense son fundamentales los trabajos de Anastasio Rojo Vega, «El negocio del libro en Medina del Campo, ss. XVI y XVII», Investigaciones históricas, VII, 1987, págs. 17-26; «Los grandes libreros españoles y América», Cuadernos hispanoamericanos, D, 1992, págs. 115-132; y «Comercio e industria del libro en el noroeste peninsular: Siglo XVI», El libro antiguo español, II, Salamanca-Madrid, Ediciones de la Universidad, Biblioteca Nacional, 1992, págs. 425-430.

${ }^{16}$ La serie de impresiones medinenses del siglo XVI puede conocerse con precisión gracias a la obra clásica de Cristóbal Pérez Pastor, op. cit. En dicha secuencia se observa un sintomático cese de actividades entre los años 1559 y 1561, trienio en que no se registra ningún impreso. El dato resulta todavía más significativo si se considera que, entre 1550 y 1558, vieron la luz 65 ediciones impresas en Medina del Campo.

${ }_{17}$ Un detallado análisis del contenido de la pragmática de 1558, así como de sus repercusiones para el negocio editorial, puede leerse en José Manuel Lucía Megías, «La Pragmática de 1558 o la importancia del control del Estado en la imprenta española», Indagación: Revista de historia y arte, IV, 1999, págs. 195-220.

${ }^{18}$ La evolución de la censura a lo largo del siglo XVI ha sido estudiada, entre otros, por Antonio Márquez, Literatura e Inquisición en España (1478-1834), Madrid, Taurus, 1980; José Martínez Millán, «Aportaciones a la formación del Estado Moderno...», op. cit.; y Virgilio Pinto Crespo, en varias publicaciones: «Institucionalización inquisitorial y censura de libros», La Inquisición española. Nueva visión, nuevos horizontes, Joaquín Pérez Villanueva, dir., Madrid, Siglo XXI, 1980, págs. 513-535; Inquisición y control ideológico en la España del siglo XVI, Madrid, Taurus, 1983; y «Pensamiento, vida intelectual y censura en la España de los siglos XVI y XVII», Edad de Oro, VIII, 1989, págs. 181-192.

${ }^{19}$ Los documentos generados por la visita a las librerías de 1572 son transcritos y comentados por José García Oro y M. a José Portela Silva, Felipe II y los libreros: actas de las visitas a las librerías del Reino de Castilla en 1572, Madrid, Cisneros, 1997. 
Mateo del Canto, quien adquirió los derechos de las princeps nueve años atrás, sin embargo, disfruta de sus últimos meses de vida. Instalado en Medina del Campo al menos desde 1547 — fecha del protocolo notarial más antiguo de entre los conservados ${ }^{20}$ — ha ejercido durante cinco lustros las más variadas labores en aquel bullicioso negocio de la cultura impresa. En sus inicios, obligado por la escasez de recursos, trabaja al servicio de tres mercaderes lyoneses -Claude Rainaud y Pedro y Jusepe Osandón ${ }^{21}$ — que operan en el entorno de las ferias. Mateo del Canto es en este tiempo tan sólo un subordinado que, sujeto a estrictas condiciones laborales, coordina la importación y venta de libros traídos desde la central francesa al almacén medinense. Más adelante, entre 1554 y 1568, su nombre aparece ligado al de Francisco del Canto en numerosas impresiones. Es en este período cuando alterna el negocio de librería con el taller de imprenta, el momento en que la estrecha colaboración con su hermano da algunos de sus más valiosos frutos, como el Lazarillo de Tormes ${ }^{22}$ (1554) o el Inventario de Villegas (1565). Tres años más tarde, en 1568, Mateo del Canto abandona la imprenta. Vende las prensas y los tipos ${ }^{23}$ para dedicarse exclusivamente al negocio editorial, donde poco a poco amplía sus horizontes. Conocemos, por ejemplo, sus acuerdos comerciales con Francisco López ${ }^{24}$, librero de Su Majestad residente en la Corte, con quien llevaría a cabo un intenso intercambio de género. Su definitivo entronque con los grandes de Medina, no obstante, llega en 1570: el 9 de octubre, Beatriz Delgado del Canto, su hija legítima, casa con Benito Boyer ${ }^{25}$. La novia recibe en concepto de dote las dos casas de la calle de la Carpintería que por aquel entonces eran ya verdaderos almacenes de libros — guardaban más de 22.000 volúmenes a la muerte de

${ }^{20}$ Se trata de una carta de poder de Mateo del Canto a Hernando de Frías, mercader de la villa, para que cobre en su nombre 18.870 y 2.325 mrs. del Dr. Avilés. Está fechada el 28 de junio de 1547 y pertenece a los protocolos del escribano Juan Losa. El documento lo recoge Pérez Pastor, op. cit., pág. 147.

${ }^{21} \mathrm{El}$ asiento de servicio se encuentra entre los protocolos notariales de Miguel Quadrado del año 1549. Su transcripción está recogida en Pérez Pastor, op. cit., págs. 427-428.

${ }^{22}$ El Lazarillo de Tormes impreso por Francisco del Canto en 1554 puede leerse en edición facsímil, Mérida, Junta de Extremadura, 1996, tras su feliz hallazgo en una vieja casa de Barcarrota.

${ }^{23}$ El 5 de mayo de 1568 Mateo del Canto vende a Vicente de Millis dos prensas, 16 suertes de matrices, 27 quintales de letras fundidas y los demás aparejos de su imprenta, tras lo que abandona definitivamente el taller. El documento se conserva entre los protocolos de Francisco de Vitoria del año 1568, y puede leerse, en su parte fundamental, en Pérez Pastor, op. cit., pág. 438.

${ }^{24}$ La carta de poder de Mateo del Canto a Francisco López, librero de Su Majestad residente en la Corte, se halla entre los protocolos notariales de Francisco de Vitoria del año 1568. Lo recoge Pérez Pastor, op. cit., pág. 439.

${ }^{25} \mathrm{La}$ carta de arras de dicho matrimonio se conserva en el A.H.P.V., Protocolo 7059 (Íñigo de Argandoña, 1570), fol. 658. Ha sido transcrita y comentada en Vicente Bécares y Alejandro Luis Iglesias, La librería de Benito Boyer: (Medina del Campo, 1592), Salamanca, Junta de Castilla y León, 1992, pág. 11. 
Mateo del Canto - cuyo valor, en el momento de concertarse el matrimonio, asciende a 2.000 ducados.

Alcanzada la prosperidad en su madurez, sin embargo, la vida de Mateo del Canto está próxima a su fin, y se agota definitivamente en fechas decisivas para el segundo Inventario. Sabemos que aún vivía en las postrimerías de 1574 — varios meses después de que Villegas obtuviera el nuevo privilegio- cuando actúa como contador en la revisión de cuentas de los bienes que quedaron de Alberto Colón ${ }^{26}$; pero tenemos la certeza, gracias a varios protocolos notariales, de que murió antes de finalizar el año siguiente. No hay ninguna duda: Catalina Delgado figura ya como su viuda en un documento rubricado en Medina del Campo el 31 de agosto de $1575^{27}$. Así las cosas, es muy posible que el famoso librero no participara finalmente en el proyecto junto a su hermano por la sencilla razón de que no tuvo tiempo para hacerlo.

Si Antonio de Villegas hubiese apalabrado con Mateo del Canto, allá por 1574, el traspaso de los derechos recién adquiridos, lo cierto es que se habría quedado repentinamente sin editor. Para vender el privilegio necesitaría contar con la confianza de algún otro librero o mercader de libros que estuviera dispuesto a apostar por sus poemas. Quizás esto explicaría el retraso del proyecto y el recurso a ciertas estrategias editoriales que se manifiestan con claridad en la composición del nuevo Inventario.

Dos años habrían de pasar para que Antonio de Villegas volviera a dar señales de vida. Entrado el otoño de 1576, el escritor se dirige una vez más a la Cámara de Castilla con intención de conseguir licencia de impresión para varios poemas que desea añadir al libro. En los preliminares ha quedado constancia de todo ello a través del informe emitido por el censor:

He visto esta Disputa entre Aiax y Vlixes, y parésceme digna de publicarse, y que empremirse con las demás obras que están con ella no puede auer inconueniente. En Madrid, a veynte de octubre de mil y quinientos y setenta y seys años.

Ioan López de Velasco ${ }^{28}$

Juan López de Velasco, censor al servicio de la Cámara de Castilla, da su beneplácito para que los nuevos versos se puedan imprimir junto a los antiguos. Inmediatamente después, el rey extiende el pertinente privilegio donde se detallan diversas circunstancias adicionales. Está fechado en El Pardo, a 25 de

${ }^{26}$ El documento está fechado a 27 de noviembre de 1574 y pertenece a los protocolos notariales de Alonso Montero. Un extracto del mismo puede consultarse en Pérez Pastor, op. cit., pág. 444.

27 Véase A.H.P.V., Protocolo 6716 (Diego de Espinosa, 1575), fols. 1265-1266v.

28 Antonio de Villegas, Inventario, Medina del Campo, Francisco del Canto, 1577, preliminares, fol. $4 \mathrm{v}$. 
octubre de 1576. Lo firma, en nombre de Su Majestad, Antonio de Eraso ${ }^{29}$, quien actúa como secretario en el lugar que ocupara su padre muchos años antes. Curiosamente, él mismo fue quien intercedió por Villegas para agilizar los trámites en 1565. La historia del Inventario, una vez más, se cruza en el camino de este insigne cortesano, aunque en este caso actúe simplemente de oficio.

La obra con las composiciones recientemente añadidas sale de las prensas de Francisco del Canto pocos meses más tarde, ya en 1577. Jerónimo de Millis es ahora el nuevo editor, como se lee en la portada: «A costa de Hierónymo de Milis, mercader de libros». Antonio de Villegas, pues, encontró en dicho librero adecuado sustituto al fallecido Mateo del Canto.

Jerónimo de Millis encarnaba por entonces en aquel microcosmos la figura del gran mercader dedicado prioritariamente a la importación y venta de libros extranjeros. Es cierto que, como capitalista de posibles, costeaba cuando lo estimaba oportuno alguna edición, mas el grueso de su actividad se centraba en el comercio. Por esa razón, las más de las veces aparece firmando importantes operaciones financieras para traer a Castilla grandes partidas de libros salidos de Lyón ${ }^{30}$. La entidad del personaje queda en evidencia por dos significativos testimonios: Millis actúa como testigo del testamento dictado por Simón Ruiz Embito $^{31}$, insigne patricio de la villa; mientras que en 1592 es una de las reconocidas autoridades que realiza el inventario de la librería de Benito Boyer tras su fallecimiento ${ }^{32}$. Sólo quien pertenece a lo más granado de la sociedad medinense puede participar en negocios de tanta trascendencia. El poder y prestigio de Jerónimo de Millis, pues, debieron pesar considerablemente a la hora de preparar la nueva composición del Inventario, cuyas modificaciones pretenden hacerlo más atractivo a los lectores.

Que la adición de nuevos materiales forma parte, fundamentalmente, de una estrategia editorial parece confirmarse por varias circunstancias. En primer lugar, por la propia dinámica de los acontecimientos sugerida por los preliminares y los documentos reseñados, que nos presenta al poeta medinense, entrado el año 1576 , con un privilegio recientemente adquirido pero sin editor a quien

${ }^{29}$ Una pequeña biografía sobre Antonio de Eraso se ofrece en José Martínez Millán, Felipe II (1527-1598). La configuración de la monarquía hispana, Salamanca, Junta de Castilla y León, 1998, págs. 367-368.

30 Así son descritas las actividades comerciales de Jerónimo de Millis en la breve biografía ofrecida por Pérez Pastor, op. cit., pág. 497, donde se resume la información extraída de los protocolos notariales.

${ }^{31}$ La prominente figura de Simón Ruiz Embito puede conocerse a través del trabajo clásico de Henry Lapeyre, Une famille de marchands, les Ruiz de Medina, Paris, Armand Colin, 1955.

32 A dar cuenta del inventario de la librería de Benito Boyer, realizado por Juan de Terci y Jerónimo de Millis en 1592, fue dedicada la monografía de Vicente Bécares y Alejandro Luis Iglesias, op. cit. 
venderlo. Tras dos años de espera, y con la consiguiente molestia, se ve obligado a gastar tiempo y dinero para solicitar una nueva licencia que le permita incluir ciertos poemas en el Inventario. Sin ellos, muy probablemente, el poderoso Millis no financiaría la edición. Antonio de Villegas, en consecuencia, se habría plegado a sus designios para no perder los derechos obtenidos en 1574.

La descripción física del libro no hace sino confirmar estas impresiones. En primer lugar, por el hecho de que los nuevos versos no alteren la distribución original, sino que pasen a ubicarse inmediatamente detrás del Abencerraje, como un apéndice de la princeps, cuya estructura no se ve alterada en absoluto. Si en 1565 todos los materiales fueron ordenados conforme a cierta lógica formal y temática, ahora no sucede nada parecido. No hay reelaboración, ni replanteamiento orgánico del conjunto - los nuevos poemas, según el criterio empleado en 1565, deberían situarse junto a los de metro castellano- sino yuxtaposición y desequilibrio que poco importan a los profesionales del libro.

Finalmente, el contenido de la portada deja pocas dudas acerca de las intenciones del librero. Allí se anuncia a bombo y platillo, como interesantísima novedad, que «va agora de nuevo añadido un breve retrato del Excelentísimo Duque de Alva. Y una questión y disputa entre Aiax Telamón y Ulixes, sobre las armas de Achiles». En el frente del libro, en su cara visible, es donde el editor ha de informar a los lectores acerca de los nuevos alicientes del producto que se pone a la venta. Jerónimo de Millis, tras haber remozado la pieza, así lo hace.

En fin, todas estas prácticas han de ponerse en relación, desde una perspectiva más general, con otros procedimientos que, en paralelo, pretenden incrementar los rendimientos económicos de la edición. Uno de los más llamativos es la reducción del formato ${ }^{33}$. Como se aprecia a simple vista, los ejemplares compuestos en $1577^{34}$ poco tienen que ver con los cuidados volúmenes en cuartos de 1565 .

El texto se ofrece ahora en el seno de un pequeño librillo en octavos cuya materialidad carece de la presencia del original. El cómputo de pliegos, sin embargo, no arroja un resultado muy diferente: frente a los dieciséis y medio de la princeps, el Inventario de 1577 está compuesto —al margen de los preliminares - por dieciocho cuadernos de ocho hojas cada uno (A-S) en los que tienen cabida los 144 folios que, señalados en el recto con numeración árabe, completan el volumen. Por consiguiente, para ubicar la nueva composición en

33 A la hora de emprender la descripción bibliográfica del Inventario sigo las explicaciones de José Simón Díaz, El libro español antiguo: Análisis de su estructura, Kassell, Edition Roberfer, 1983; y Philip Gaskell, Nueva introducción a la bibliografía material, Gijón, Trea, 1999, trad. Consuelo Fernández Cuartas y Faustino Álvarez Álvarez.

${ }^{34}$ La descripción bibliográfica del Inventario de 1577 puede consultarse en Cristóbal Pérez Pastor, op. cit., págs. 199-218; y Antonio de Villegas, Inventario, ed. cit., págs. 26-27. 
el cuerpo del libro sólo fueron necesarios doce folios más que para la príncipe —un pliego y medio_, lo cual resulta muy llamativo si se considera que el número de versos se ha incrementado en más de una cuarta parte y que el tamaño del folio se ha reducido a la mitad.

En efecto, el cambio de formato, unido al escaso aumento de cuadernos, permite un importante ahorro de papel que repercute en la inversión del librero, así como en el precio final de los ejemplares. En 1577 ambos disminuyeron de manera proporcional, ya que el papel representaba la partida más costosa del proceso de producción del libro ${ }^{35} \mathrm{y}$, de hecho, era el único factor ponderado por el Consejo de Castilla a la hora de establecer la tasa de un volumen.

Y si el octavo permite utilizar menos materia prima, también es preciso reseñar que acelera sin duda las tareas mecánicas de impresión. El motivo se comprende sin demasiada dificultad: si para completar cada cara del pliego de la princeps se necesitaron dos golpes de barra, para imprimir idéntico segmento en el pequeño formato de la segunda se requirió justamente la mitad de trabajo, es decir, un solo movimiento, pues la superficie de cada pliego — si nos atenemos a las signaturas y reclamos - se había reducido también a la mitad. Así, para estampar cada cuaderno en los 1.558 ejemplares que constituyeron la edición — considerando el blanco y la retiración - fueron imprescindibles 3.116 descensos del cuadro. Esto significa que, si el componedor conseguía mantener el ritmo de los demás operarios, era posible terminar dos pliegos de la obra en cada jornada, el equivalente a 6.232 tiradas. A esta velocidad, el Inventario de 1577 pudo imprimirse, con una sola prensa, en unos diez días, poco más o menos. Con ello, los costes de producción, de nuevo, disminuían considerablemente ${ }^{36}$.

Desde el punto de vista técnico, el procedimiento que el impresor llevó a cabo para reducir el tamaño de la página no consistió en añadir una nueva doblez al pliego de $60 \times 40 \mathrm{~cm}$., sino en dividir éste, tras la impresión, en dos mitades iguales para trabajar con unidades básicas de $40 \times 30 \mathrm{~cm}$. Este nuevo pliego de pequeñas dimensiones, ya sí, es doblado tres veces para dar lugar a cuadernos de ocho folios y dieciséis páginas que miden, aproximadamente, $10 \times 15 \mathrm{~cm}$. Si, como en el caso del ejemplar guardado en la Biblioteca Nacional de Madrid, los márgenes han sido recortados con posterioridad, no es extraño que su medida definitiva sea de $10 \times 14 \mathrm{~cm}$.

Considerando la acuciante necesidad de ahorrar esfuerzos para rentabilizar las horas de trabajo, debemos pensar que dichos pliegos de $40 \times 30 \mathrm{~cm}$. no

35 Véase Anastasio Rojo Vega, Impresores, libreros y papeleros en Medina del Campo y Valladolid en el siglo XVII, Salamanca, Junta de Castilla y León, 1994.

${ }^{36} \mathrm{El}$ proceso de producción del libro en los antiguos talleres de imprenta ha sido descrito por Jaime Moll, «La imprenta manual», Imprenta y crítica textual en el siglo de oro, op. cit., págs. 13-27. 
constituyeron unidades independientes hasta después de haber recibido la tinta. Esto implica que, en cada forma de $60 \times 40 \mathrm{~cm}$., tenían cabida hasta dieciséis páginas del nuevo formato, las cuales correspondían no a uno, sino a dos cuadernos (A-B, C-D, E-F, G-H, I-K, L-M, N-O, P-Q y R-S) que se estampaban simultáneamente en el mismo pliego. Cada uno ocupa entonces la mitad del espacio disponible. Sólo después, el pliego sería segmentado y se iniciarían las dobleces previas a la encuadernación.

El paso de un formato a otro - de cuartos a octavos - lleva aparejados una serie de cambios que afectan al cuerpo de los tipos móviles, a las dimensiones de los grabados y, en fin, al tamaño de todas las piezas que intervienen en la impresión, las cuales, por regla general, han de reducirse más o menos a la mitad. No obstante, es interesante constatar cómo algunos elementos decorativos empleados en la princeps son utilizados de nuevo en la edición de 1577 a pesar de su tamaño. Nos referimos a las letras capitales y al grabado con el escudo real, que ahora se presenta en páginas interiores. Evidentemente, si antes estas piezas ocupaban un espacio proporcionado entre los márgenes del cuarto, ahora, engastadas en un librillo en octavos, su dimensión parece desmesurada junto a las nuevas letrerías que las acompañan.

La relativa frecuencia de estas estrategias editoriales, por consiguiente, debió provocar que impresores como Francisco del Canto terminaran siendo verdaderos expertos en la materia, hasta el punto de saber calibrar, con precisión certera, las consecuencias de trasladar unos formatos a otros. Así lo ponen de manifiesto los dos Inventarios, cuya diferente extensión se debe al incremento de composiciones, no a las estrecheces de la nueva página. Es más, entre los márgenes del octavo, el impresor ha logrado embutir en 1577 más líneas que entre los amplios cuartos de la princeps, de tal manera que, paso a paso, la segunda edición gana terreno a la primera y consigue introducir en un menor número de folios los mismos contenidos.

Así pues, en la trayectoria del Inventario se cumplen las mismas regularidades observadas en otras secuencias editoriales de la época ${ }^{37}$ : por una parte, adición de nuevas composiciones, que se colocan al final del volumen para incrementar su atractivo; por otra, reducción del formato para abaratar los costes de producción y disminuir el precio de venta. Las limitaciones de la imprenta española obligaban y eran necesarios estos recursos para sacar adelante una edición rentable.

${ }^{37}$ Un caso análogo de manipulación editorial se observa en la tradición de La Diana de Jorge de Montemayor, muchas de cuyas ediciones incluyen materiales nuevos para reforzar el atractivo del libro. A dar cuenta de esta rica trayectoria dedicó un completo estudio Eugenia Fosalba Vela, La Diana en Europa: ediciones, traducciones e influencias, Barcelona, Seminari de Filología i d'Informática. Department de Filologia Espanyola. Universitat Autónoma, 1994, donde se ofrece una exhaustiva descripción bibliográfica de todas las ediciones antiguas hoy conocidas. 
A pesar de todo $-\mathrm{y}$ aun siendo predominante la vocación comercial en estos procesos - el contenido de las piezas añadidas no resulta indiferente para comprender las circunstancias que rodearon la génesis del segundo Inventario. Hasta ocho nuevos poemas en metro castellano se incorporan al libro de Villegas en 1577. Su organización interna responde a un criterio muy semejante al empleado en 1565 para las distintas secciones ${ }^{38}$ :

En primer lugar se sitúan dos composiciones que reelaboran temas de la Antigüedad, como son la famosa Disputa entre Ayax Telamón y Ulises sobre las armas de Aquiles y el Llanto de Pílades por la muerte de Orestes, su gran amigo. La primera está dedicada a don Fadrique de Toledo, hijo del duque de Alba, e incluye en su prefacio un glorioso retrato del veterano aristócrata.

A continuación aparecen cuatro piezas de inspiración cancioneril que perseveran en el estilo del primer Inventario, como son A una dama enviándola un espejo, A un ventalle que envió a una dama, una nueva Fantasía de amor y una Glosa a un mote que traía el condestable don Bernardino en sus reposteros. Nada que no conociera ya el lector: estrofas tradicionales en octosílabo, temática del amor no correspondido, juegos conceptuales, prácticas literarias consagradas...

En último término, para cerrar la edición de 1577, el medinense escoge dos breves poemas destinados a ensalzar la belleza y las virtudes de dos nobles damas. Están dedicados A la señora Victoria Colonna, marquesa de Pescara y A Doña Juana de Castro, hija del conde de Puñoenrostro.

Poco más habría que decir en lo que respecta a los valores estéticos de los materiales añadidos, pues no manifiestan evolución alguna ni en lo formal ni en lo temático con respecto al volumen original.

Desde el punto de vista editorial, sin embargo, se aprecia una clara distinción funcional entre la Disputa entre Ayax Telamón y Ulises y el resto de composiciones añadidas. Mientras la primera representa el principal reclamo comercial de la edición, las demás piezas parecen actuar fundamentalmente como material de relleno ${ }^{39}$. En efecto, los breves poemas que cierran el libro consti-

${ }^{38}$ En el Inventario de 1565, el cuerpo central del cancionero fue dividido en dos bloques bien diferenciados: los poemas al estilo tradicional castellano, en primer lugar, y las composiciones al modo italiano, a continuación. Ambos segmentos se inauguraban con sendas reelaboraciones de episodios clásicos: la Oración de la reina Dido a Eneas y la Historia de Píramo y Tisbe, respectivamente.

${ }^{39}$ La Disputa entre Ayax Telamón y Ulises concluye a mitad del penúltimo pliego (R) dejando cinco páginas en blanco de las dieciséis que lo componían. No obstante, la impresión en parejas de los pliegos (R-S) obligaba a rellenar por completo un nuevo cuaderno (S) si no se deseaba desperdiciar gran cantidad de papel. De ahí que el variado elenco de poemas situado al final del Inventario no sólo se utilice para cerrar el pliego $\mathrm{R}$ - como sería de esperar - sino que se prolongue hasta alcanzar la última línea del cuaderno $\mathrm{S}$, ya que a ojos del impresor ambos constituían una unidad de producción que sólo más adelante sería segmentada para la encuadernación. 
tuyen, desde la perspectiva del impresor, unidades fácilmente adaptables a sus necesidades y, como era de esperar, sirvieron a Francisco del Canto para completar exactamente los dieciocho pliegos del volumen, de tal manera que no desperdició un gramo de papel en aquel encargo. Por ello, es lícito postular que no todo el corpus incorporado en 1577 fue compuesto a propósito para la ocasión. Antes al contrario, es muy probable que muchos de estos versos llevaran años en el cartapacio de Villegas y que sólo ahora, debido a las exigencias de la imprenta manual y tomados como elemento recurrente, hallen la ocasión propicia para saltar a la transmisión impresa. De hecho, algunas obras se ajustan mejor a una cronología antigua, como el poema dedicado a Victoria Colonia, cuyo momento de esplendor y máxima influencia se sitúa en las décadas anteriores a 1550, nunca después de 1565 .

La Disputa entre Ayax y Ulises, en cambio, sí fue concebida en aquellas jornadas de madurez. En primer lugar, porque se trata de una extenso poema - comparable a los mayores de la princeps - cuya enjundia y relevancia parecen indicar que, de haber estado escrito en 1565, habría ocupado un lugar preeminente en el Inventario a la altura de la Historia de Píramo y Tisbe. Pero sobre todo porque el Retrato del duque de Alba que sirve de prólogo a la Disputa aporta datos históricos concretos que confirman la redacción tardía de sus versos. En función de los mismos podemos afirmar, con toda seguridad, que el poema nació en un momento situado entre 1574 —año en que el duque de Alba regresa a España- y 1576 - fecha del nuevo privilegio-. En consecuencia, es lo más razonable postular que la composición en su conjunto - la Disputa entre Ayax y Ulises - no fuera proyectada hasta entonces. Las referencias que sustentan nuestro planteamiento se refieren a la biografía de don Fadrique, heredero de la Casa de Alba, a quien están dedicadas las siguientes estrofas del poema:

Retrato del duque de Alba, vv. 25-32:

Quando salistes de España por la Real Magestad, de tristeza y soledad en mil lágrimas se baña.

Y luego que a Flandes fuystes, mostrastes tal valentía, que aún no está la sangre fría de las victorias que huvistes ${ }^{40}$.

${ }^{40}$ Inventario, 1577 , fol. $113 \mathrm{v}$. 
El primer acontecimiento al que se alude tuvo lugar en 1568, cuando, por orden directa de Felipe II, don Fadrique fue desterrado a Orán por haberse casado en secreto con doña Magdalena de Guzmán. Más adelante fue perdonado y enviado a Flandes, tal y como recuerdan también estas estrofas, donde combatió contra los insurrectos junto a su padre ${ }^{41}$. Si consideramos que las dos vivencias se abordan como parte del mismo pasado, es obligado pensar que ambas fueron contempladas desde una perspectiva lejana que, en ningún caso, pudo tener sentido antes de 1574 , fecha en la que don Fadrique regresa a la Península desde los Países Bajos. Por ello, el Retrato del duque de Alba y la misma Disputa entre Ayax y Ulises sobre las armas de Aquiles debieron salir de la pluma de Villegas en un tiempo posterior a los sucesos rememorados por el poema. Con estas observaciones, ya no hay duda, queda confirmada la cronología apuntada por los preliminares.

El hecho de que Villegas adapte un antiguo episodio de la guerra de Troya en la Disputa entre Ayax y Ulises no sorprende en absoluto. Sí lo hace, en cambio, la alabanza a don Fernando Álvárez de Toledo y, mucho más, la dedicatoria a don Fadrique de Toledo, su hijo. Y es que, si hasta el momento todos los indicios habían relacionado al escritor medinense con los grupos cortesanos de inclinación humanista, ahora sus preferencias parecen haber dado un giro radical $^{42}$.

El duque de Alba — aristócrata, caudillo, político y patrón- era la cabeza visible no sólo de una facción cortesana, sino de todo un modo de entender la Monarquía que se oponía frontalmente al criterio de tolerancia religiosa y respeto a los poderes locales propio de los ebolistas. En ese sentido, el duque era partidario de una Monarquía fuerte cimentada en Castilla y en instituciones centralizadas que, desde la Península, permitieran ejercer un control directo sobre los distintos reinos de los Habsburgo. Para ello era imprescindible defender a ultranza el catolicismo, toda vez que la herejía había demostrado sus poderes subversivos. Por si fuera poco, la tradición de cruzada y la espiritualidad intransigente y formalista en la que se había criado hacían que abordara el problema religioso como una cuestión de principios más que como una cuestión de Estado. De ahí su mentalidad y su política en Flandes, que tan honda huella dejaran para la historia. Por todo ello, el duque de Alba se había convertido, a media-

41 Todos los datos biográficos del duque de Alba y de don Fadrique han sido tomados de William S. Maltby, El Gran Duque de Alba. Un siglo de España y de Europa (1502-1582), Madrid, Turner, 1985, Eva Rodríguez, trad.

${ }^{42} \mathrm{La}$ trayectoria e ideología de las distintas facciones que se disputaron el poder en la Corte española a lo largo del siglo XVI ha recibido adecuado tratamiento en José Martínez Millán, dir., La Corte de Carlos V, 5 vols., Madrid, Sociedad Estatal para la Conmemoración de los Centenarios de Felipe II y Carlos V, 2000; y José Martínez Millán y Santiago Fernández Conti, dirs., La Monarquía de Felipe II. La casa del rey, 2 vols., Madrid, Fundación Mapfre-Tavera, 2005. 
dos de la década de 1570, en un auténtico mito para los castellanos, un héroe que había defendido los intereses del rey y del emperador en todos los campos de batalla europeos y norteafricanos. Desde hacía más de cuarenta años, franceses, berberiscos, alemanes, turcos, italianos y holandeses habían sufrido la prodigiosa capacidad militar de don Fernando, algunas de cuyas hazañas, como la de Mühlberg, quedaron grabadas en la memoria colectiva.

Vuelto de Flandes en 1574, sin embargo, el tremendo fracaso de su política de terror y beligerancia le habían hecho perder el favor real y su carrera se hallaba en el punto más bajo desde hacía décadas. Por si fuera poco, Antonio Pérez — el hombre más poderoso de la Corte tras la muerte de Diego de Espinosa y Ruy Gómez de Silva - y la princesa de Éboli no cesaban de acosarlo y de intrigar contra sus intereses. Ése es el momento en que Antonio de Villegas compone su laudatorio Retrato del duque de Alba.

Pero más sorprendente si cabe es la dedicatoria de la Disputa de Ayax y Ulises a don Fadrique de Toledo. A la altura de 1574 pocos personajes en Castilla habían caído más bajo que él. Salpicado por el escándalo de su matrimonio no autorizado con doña Magdalena de Guzmán, había sido desterrado por el rey en 1568. Carente de las capacidades del padre, fue enviado finalmente a Flandes, donde el duque pretendía recuperar su fama y su prestigio situándolo al frente de las tropas. El ejército que debía combatir a los insurgentes holandeses, sin embargo, cosechó una humillante derrota en la campaña de 1572 y 1573 que terminó con la incipiente carrera política de don Fadrique. Enfermo y defenestrado, regresa a Madrid junto al duque en 1574. Fue apartado de la Corte y encarcelado. En los doce años que le quedaban de vida, jamás remontaría el vuelo. Por eso resulta tan extraño escuchar de Villegas tan sonoras alabanzas que en poco o nada se correspondían con la realidad. ¿Exaltación del héroe colectivo?, ¿amistad personal?, ¿dependencia profesional?, ¿cambio de facción?, ¿desengaño de madurez? Es difícil precisar la respuesta.

Y es que cuantas más circunstancias se consideran, más evidente resulta la contradicción. Al final del volumen impreso en 1577, sin ir más lejos, hallamos nuevos argumentos. El poema dedicado a Victoria Colonna, marquesa de Pescara, posee unas connotaciones políticas y religiosas que rozan lo heterodoxo. En efecto, la aristócrata italiana — que vivió durante la primera mitad del siglo XVI - aparte de contribuir activamente al desarrollo de la cultura de su época y de mantener una estrecha amistad con artistas de la talla de Miguel Ángel, perteneció al círculo más íntimo de Juan de Valdés, con quien compartió conventículo en el exilio napolitano ${ }^{43}$. Por si fuera poco, esta egregia dama

${ }^{43}$ La historia del conventículo formado en Italia por Juan de Valdés ha sido tratada en José C. Nieto, Juan de Valdés y los orígenes de la Reforma en España e Italia, México, Fondo de Cultura Económica, 1979. 
no dudaría en plasmar el ideario religioso del grupo — cercano al luteranismo por sostener creencias como la justificación por la fe y prácticas como la traducción de la Biblia - en muchas de sus Rimas que, sin duda, fueron conocidas por Villegas, quien ensalza, junto a la virtud y belleza del personaje, sus dotes literarias.

Figuras como el duque de Alba y Victoria Colonna armonizan mal en el mismo libro. Representan los caminos opuestos de la encrucijada histórica que marcaría toda la centuria. Ambos personajes simbolizan, quizás, dos momentos en la vida del escritor, cuya evolución habría corrido pareja al tren de los tiempos: tras una juventud marcada por el humanismo, el ideal de tolerancia y las formas de espiritualidad intimista; ya en la madurez, alejado de la utopía, se habría decantado por la autoridad, la fuerza y el confesionalismo intransigente — la postura de Alba - destinados a salvaguardar el Imperio Habsburgo y el catolicismo ante la rebelión de los súbditos holandeses y el avance del protestantismo ${ }^{44}$. O quizás no fuera tanto y se trate simplemente de un ejercicio de adulación, sin mayores implicaciones ideológicas, dirigido al poderoso del que se espera alguna recompensa... Con los datos de que disponemos en la actualidad, en cualquier caso, parece aventurado emitir un juicio definitivo sobre el particular.

La pequeña historia del Inventario, de todos modos, no concluye siquiera en 1577, pues presenta algún episodio que sobrepasa las fronteras de aquella fecha. Hemos tenido noticia de estas circunstancias a través de un documento notarial $^{45}$ firmado, de su puño y letra, por Antonio de Villegas.

Dicho documento es, en esencia, la plasmación oficial del acuerdo al que Antonio de Villegas — escritor - y Jerónimo de Millis —editor- llegaron para dirimir sus diferencias en torno a los derechos de explotación del Inventario de 1577. Está firmado en Medina del Campo, a 28 de noviembre de 1578, ante el escribano público Diego de Espinosa. Con su apoyo, es posible reconstruir el desenlace de la pequeña historia del Inventario. Así comienza:

\section{Para Gerónimo de Miles, librero:}

Conosçida cosa sea a los que esta pública escriptura vieren, cómo en la noble villa de Medina del Campo, a veinte e ocho días del mes de nobiembre, año del Señor de mill e quinientos e setenta e ocho, pasó ante mí, Diego de Espi-

${ }^{44} \mathrm{La}$ evolución desde un período inicial de pluralidad y tolerancia con Carlos $\mathrm{V}$ a otro de intransigencia confesional con Felipe II puede seguirse en José Martínez Millán, «Del humanismo carolino al proceso de confesionalización filipino», Andrés Laguna: humanismo, ciencia y política en la Europa Renacentista, Valladolid, Junta de Castilla y León, 2001, págs. 123-159.

${ }^{45}$ El documento se guarda en el Archivo Histórico Provincial de Valladolid bajo la signatura A.H.P.V., Protocolo 6718 (Diego de Espinosa, 1578), fols. 466-469v. Supe de su existencia por gentileza de Anastasio Rojo Vega, quien me indicó su localización el 9 de abril de 2003 en el Palacio de los Vivero de Valladolid. 
nosa, escribano público del número de la dicha villa e tierra, paresçió presente el señor Antonio de Billegas, vecino de la dicha villa, e dixo que por quanto la Magestad del Rei don Felipe, nuestro señor, le hizo merced e dio liçençia para que por tiempo de ocho años pudiese inprimir un libro que hizo intitulado Inventario de las obras de Antonio de Billegas con lo demás que después añadió al dicho libro de la Quistión e disputa entre Ajax y Ulises sobre las armas de Aquiles por aprovale para estos reinos segund más largo se dize en el previllexio de la dicha merçed, firmado de su real mano e refrendado de Antonio de Heraso, su secretario, fecha en Madrid, a veynte de julio de mill e quinientos e setenta e quatro años, a que se referió e le ovo aquí por inserto. E que ansí es que él, por vertud del dicho previllexio, se conçirtó con Gerónimo de Miles, mercader de libros e vecino de la dicha villa, de que ynpri-

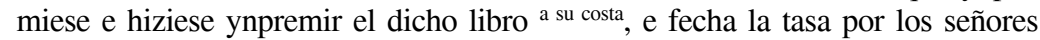
del Consejo de Su Magestad conforme al dicho previllexio, lo vendiese. E el dicho Gerónimo de Miles, en cumplimiento del dicho conçierto, lo hizo enpremir e se ynprimieron ȩierta eantidad mill e quinientos e cinquenta e ocho cuerpos de libros como parte de la ynprisión que dellos se hizo en esta villa por Francisco del Canto, ynpresor e vecino della el año de setenta e siete 46 .

Como se lee, el documento recuerda los pasos iniciales que, como era habitual, escritor, librero e impresor dieron para llevar adelante la edición: tras obtener privilegio de $\mathrm{Su}$ Majestad para imprimir sus obras, Antonio de Villegas se concertó con el mercader Jerónimo de Millis, vecino de Medina del Campo, para que hiciese imprimir los libros a su costa, y que una vez fijada la tasa por el Consejo de Castilla, los vendiese a través de su establecimiento medinense. Gracias a los derechos adquiridos con aquel concierto, Millis encargó al impresor Francisco del Canto los trabajos mecánicos de impresión. Fruto de aquel convenio salieron a la luz en 1577 los 1.558 ejemplares de que constaba la segunda edición del Inventario. Un año después, sin embargo, graves desavenencias enturbiarían aquella prometedora empresa:

E porque sobre lo que cada uno dellos havía de heredar en la dicha ynpresión se esperaba entre ellos aver pleyto e diferençia, e por la hebitar e escusar las costas e dannos dello, se conçertaron en que el dicho Antonio de Billegas vendiese, cediese e renunçiase en el dicho Geronimo de Miles dichos mill e quinientos e quarenta e ocho todos los libros que hasta hoi estan ynpresos de las dichas obras del dicho Antonio de Billegas para que él los venda por la tasa que dellos está fecha por los señores del Consejo de Su Magestad, que es a tres maravedís el pliego, como parece por el testimonio que dello dio Pedro Çapata del Mármol, secretario de Su Magestad, firmada de su nombre, fecha en Madrid, a diez e ocho de setiembre de mill e quinientos e setenta e ocho años, e que el dicho Gerónimo de Miles llevase para sí el probecho e aumento dellos sin que para el dicho Antonio de Billegas sea cosa alguna, e que por razón dello el dicho Gerónimo de Miles le diese e pagase, por la parte que dello en qualquier manera le pertenesçe, mill reales de plata, que valen

\footnotetext{
46 A.H.P.V., Protocolo 6718 (Diego de Espinosa, 1578), fols. 466-466v.
} 
treinta e quatro mill maravedís en reales de contado. E el dicho Gerónimo de Miles, en cumplimiento del dicho conçierto, le dio e pagó, e él reçibió dél los dichos mill reales en esta manera: cient reales que el dicho Gerónimo de Miles en dineros pagados le dio, de que le a dado carta de pago firmada de su nombre -ésta y ella, en lo tocante a los dichos cient reales, es toda una- e los noveçientos reales que hoi dicho dia le dio e pagó el señor Ludobico Bizconte en su nombre, de los quales dichos mill reales en la forma sobredicha dixo que se dava e dio por bien contento e pagado e entregado a su voluntad ${ }^{47}$.

El 18 de septiembre de 1578 los señores del Consejo de Su Majestad fijan la tasa del volumen. Finalmente, se han cumplimentado todos los requisitos legales para la distribución y venta de la edición. En ese momento comienzan, sin embargo, las desavenencias entre Jerónimo de Millis y Antonio de Villegas. Bien porque la venta del privilegio no estuviera sellada ante notario, bien porque se incumplieran las condiciones pactadas, lo cierto es que escritor y librero discrepan sobre lo que a cada uno corresponde por la explotación del Inventario. Durante los dos meses siguientes — de septiembre a noviembre - aquella diferencia a punto está de desencadenar un proceso judicial. No obstante, antes de llegar a tal extremo, y por evitarse mayores perjuicios, ambas partes fuerzan un acuerdo que queda refrendado en el presente documento: Antonio de Villegas renunciará por siempre a sus derechos a cambio de cierta cantidad —-mil reales de plata, 34.000 maravedíes - que habrán de abonarse sin dilación. Descontados los cien reales que ya se pagaron, los novecientos restantes se sufragan el mismo día de la firma por medio de Ludobico Bizconte, cambista o mercader italiano, que actúa en representación de Jerónimo de Millis.

El documento notarial, pues, sirve como recibo de dicha transacción y como explícita renuncia a sus derechos por parte del autor, quien firma el protocolo y lo dirige a Jerónimo de Millis en reconocimiento de ambos extremos. A partir de ahí, será el mercader quien guarde como oro en paño una copia de la escritura por ser ésta garante de la nueva titularidad del privilegio. Antonio de Villegas, tras interminables discusiones, ha recibido por fin su justa recompensa. Es hora de pasar a un segundo plano. Serán otros quienes, de ahí en adelante, marquen los destinos del segundo Inventario.

Las detalladas noticias que el documento aporta, no obstante, merecen una reflexión más sosegada. La primera circunstancia que deja en evidencia es la lentitud con que avanza el proceso burocrático en el seno del Consejo de Castilla: no menos de nueve meses habrían de pasar desde la finalización de los trabajos de impresión —que como muy tarde concluyen en diciembre de 1577 - hasta la fecha en que Pedro Zapata del Mármol fija el precio de aquellos volúmenes a tres maravedíes el pliego. Por otra parte, en ese mismo esta-

47 A.H.P.V., Protocolo 6718 (Diego de Espinosa, 1578), fols. 466v-467. 
dio del proceso - que acontece en septiembre de 1578 - un censor al servicio del Consejo debía cotejar el libro con el original aprobado para dejar constancia de sus diferencias en la fe de erratas. Sin embargo, ni la tasa ni la fe de erratas figuran entre los preliminares del Inventario. $\mathrm{Y}$ es que ambas diligencias se llevaron a cabo en la Corte de Madrid varios meses después de haber sido impreso el pliego de los preliminares ${ }^{48}$, de modo que, en este punto, el estricto procedimiento establecido por la pragmática de 1558 fue alterado, probablemente, para facilitar el trabajo del impresor, acelerar la puesta en circulación de la edición e, incluso, incrementar fraudulentamente el precio del ejemplar si encontraran la ocasión propicia.

Gracias al protocolo notarial, igualmente, es posible deducir las cifras que resumen la dimensión del proyecto editorial: del Inventario impreso en 1577 salieron a la calle 1.558 ejemplares en octavos. Cada uno constaba de diecinueve pliegos — sumado el de preliminares - tasados a tres maravedíes cada uno. Por lo tanto, el volumen completo se comercializó en las librerías de Castilla a 57 maravedíes. El total de sus ventas, en consecuencia, pudo reportar a Jerónimo de Millis, propietario de los derechos, un total de 88.806 mrs., que se corresponden al precio de venta de la edición completa. El margen de beneficio del editor, por tanto, podría deducirse mediante una sencilla operación matemática: a los $88.806 \mathrm{mrs}$. habría que restar tanto la parte correspondiente al autor - 34.000 mrs. - como el coste de la impresión — cuya cuantía habría de abonarse a Francisco del Canto- y posterior encuadernación. Para que Millis sacara algún provecho de la empresa, los emolumentos del impresor y el encuadernador no podían superar, en ningún caso, los 54.806 mrs. en conjunto. Desgraciadamente no conocemos los términos de dichos acuerdos, pero es evidente que cuanto menor fuera el coste de los trabajos artesanales, mayores serían los rendimientos para Millis, y viceversa.

Antonio de Villegas, por su parte, no sale mal parado: obtiene por el privilegio 34.000 mrs., lo que supone un $38,28 \%$ de los ingresos brutos de la edición. Frente a otros casos célebres de las letras españolas donde el escritor apenas ve recompensados económicamente sus esfuerzos, lo cierto es que Villegas puede considerarse afortunado; no porque las cifras globales sean desmesuradas, sino porque, en proporción a la envergadura del proyecto, se lleva buena parte de los beneficios. Quizás el atractivo de la obra garantizaba, a ojos del editor, una buena acogida entre los lectores, por lo que resultaba rentable pagar un alto precio por los derechos. Al fin y al cabo, una vez en su poder estaría

${ }^{48}$ La impresión temprana del primer pliego queda en evidencia tanto por la fecha de la portada (1577) que encabeza aquel cuaderno, como por la ausencia de tasa y fe de erratas en los preliminares. Este procedimiento no debió ser excepcional entre aquellos impresores y libreros, pues el Inventario de 1565 presenta las mismas irregularidades. 
facultado para promover — dentro de las fronteras de Castilla - nuevas ediciones del Inventario que compensaran, en años venideros, la inversión inicial. Si lo hizo o no vuelve a ser un misterio para la historia.

Lo que sí podemos discernir es que a lo largo de aquel invierno comenzó la distribución y venta del segundo Inventario, cuyos ejemplares pronto estarían a disposición del público en la tienda de Jerónimo de Millis. Tenía varias opciones para situar el género en el mercado: por una parte, podía aprovechar el empuje de las ferias y el trasiego comercial de Medina para contratar la transacción de libros al por mayor con algún mercader o librero de otra ciudad; por otra, siempre existía la posibilidad de colocar uno por uno los ejemplares a través de su establecimiento abierto al público medinense. Así, mediante grandes partidas salidas hacia otros núcleos urbanos o con el incesante goteo de compradores que adquirían la obra para su biblioteca particular, la segunda edición del Inventario inició su difusión por toda Castilla ${ }^{49}$.

Hasta completar los últimos niveles de compraventa - la obra pasa de librero en librero hacia poblaciones cada vez más pequeñas - y llegar a los más recónditos lugares del reino podían pasar, sin demasiada dificultad, unos tres años. De ese modo, se puede postular que el Inventario - impreso por Francisco del Canto en 1577 - se puso por primera vez a la venta en la tienda de Jerónimo de Millis a finales del año 1578. No obstante, no sería hasta las ferias de mayo de 1579 cuando algún librero de Salamanca o Valladolid adquiriera un buen número de ejemplares para revenderlos en sus ciudades de procedencia. Ese año llegaría sin duda a estos primeros núcleos, de donde saltaría a otros de menor entidad y así sucesivamente. En 1582, la edición habría alcanzado ya sus límites geográficos de expansión y, seguramente, aún quedaran ejemplares a la venta varios años más tarde, casi entrada la década de $1590^{50}$.

Mucho tiempo después, entre 1613 y 1616, la memoria de estos libros aún no se había desvanecido. Son las fechas aproximadas en las que se ha situado cronológicamente el manuscrito B-46 de la Real Academia de la Historia, que contiene la Historia de Medina del Campo de Juan López Ossorio, donde Antonio de Villegas es citado entre los poetas ilustres de la villa. Es muy probable que ambos personajes se conocieran, pues Ossorio vivió en Medina del Campo desde la década de 1560. Tras varios lustros de convivencia en la villa de las ferias, esto es exactamente lo que recuerda de nuestro autor en el capítulo $\mathrm{X}$ de su obra, escrita cincuenta años después del primer Inventario:

49 Sigo las descripciones hechas por Anastasio Rojo Vega acerca del comercio editorial en Castilla, «El negocio del libro en Medina del Campo...», op. cit. y «Comercio e industria del libro en el noroeste...», op. cit.

${ }^{50}$ Los plazos de distribución y venta de las ediciones impresas en Castilla a finales del siglo XVI se conocen con precisión gracias a los datos aportados en Vicente Bécares Botas y Alejandro Luis Iglesias, op. cit. 
Pareciome poner de los primeros hijos de esta patria al famoso Antonio de Villegas, que fue honrado hidalgo de esta villa, cuyo nombre se conserva en ella por una calle que se llama el Postigo de Villegas, procediendo este nombre del apellido de sus antepasados, el cual compuso muy ingeniosas cosas, y en particular hizo en la poesía grandes obras, y no pondré aquí ninguna, por andar por el reino un libro suyo intitulado Inventario de Villegas ${ }^{51}$.

Honda huella dejó, pues, Antonio de Villegas entre sus vecinos, hasta el punto de que su familia dio nombre a una calle, el «Postigo de Villegas», que podría corresponder a alguna pequeña puerta abierta en las murallas de Medina del Campo. Ossorio recuerda también su estirpe hidalga así como su fama de poeta. Pero lo que más nos interesa para nuestro propósito es confirmar que, bien entrado el siglo XVII, el cronista medinense no copia ninguna de sus obras «por andar por el reino un libro suyo intitulado Inventario de Villegas».

La obra, por consiguiente, conserva plenamente su vigencia y su popularidad mucho tiempo después de haber sido escrita. Harían falta algunos años más para que los 3.000 ejemplares que constituyeron sus dos ediciones terminaran de extinguirse. Todos los libros desaparecieron excepto dos, que hoy representan las ruinas de una empresa cultural en la que Antonio de Villegas, hidalgo de Medina del Campo, empeñó casi treinta años de su vida.

51 Tomado de la impresión realizada por Ildefonso Rodríguez y Fernández, Historia de Medina del Campo, Madrid, San Francisco de Sales, 1903-1904, págs. 206-207. 